\title{
Higher incidence of perineal community acquired MRSA infections among toddlers
}

\author{
Alexis C McCullough ${ }^{1}$, Melissa Seifried ${ }^{1}$, Xiaochen Zhao ${ }^{2}$, Jeffrey Haase ${ }^{3}$, William J Kabat ${ }^{4}$, Ram Yogev ${ }^{4}$, \\ Robert M Blumenthal ${ }^{5,6}$ and Deepa Mukundan ${ }^{2,5^{*}}$
}

\begin{abstract}
Background: A six-fold increase in pediatric MRSA infections, prompted us to examine the clinical profile of children with MRSA infections seen at Mercy Children's Hospital, Toledo, Ohio and to characterize the responsible strains.

Methods: Records were reviewed of pediatric patients who cultured positive for MRSA from June 1 to December 31, 2007. Strain typing by pulsed field gel electrophoresis (PFT) and DiversiLab, SCCmec typing, and PCR-based lukSF-PV gene (encodes Panton-Valentine leukocidin), arginine catabolic mobile element (ACME) and cap5 gene detection was performed.

Results: Chart review of 63 patients with MRSA infections revealed that 58(92\%) were community acquired MRSA (CAMRSA). All CAMRSA were skin and soft tissue infections (SSTI). Twenty five (43\%) patients were aged $<3$ yrs, 19 (33\%) aged $4-12$ and $14(24 \%)$ aged 13-18. Nineteen (76\%) of those aged $<3$ yrs had higher incidence of perineal infections compared to only 2(11\%) of the 4-12 yrs and none of the 13-18 yrs of age. Infections in the extremities were more common in the older youth compared to the youngest children. Overall, there was a significant association between site of the infection and age group (Fisher's Exact p-value $<0.001$ ). All CAMRSA were USA300 PFT, clindamycin susceptible, SCCmec type IVa and lukSF-PV gene positive. Nearly all contained ACME and about $80 \%$ were cap5 positive. Of the 58 USA300 strains by PFT, 55(95\%) were also identified as USA300 via the automated repetitive sequence-based PCR method from DiversiLab.
\end{abstract}

Conclusions: CAMRSA SSTI of the perineum was significantly more common among toddlers and that of the extremities in older children. The infecting strains were all USA300 PFT. Further studies are needed to identify the unique virulence and colonization characteristics of USA300 strains in these infections.

\section{Background}

Staphylococcus aureus (S. aureus) is a common human commensal organism and a clinically important invasive pathogen. Methicillin resistant S. aureus (MRSA) remains one of the most prevalent pathogens isolated from hospital patients. However, MRSA infections are increasingly arising outside of healthcare settings among individuals in the community with no established risk factors. Furthermore, the incidence of invasive community acquired MRSA (CAMRSA) disease in previouslyhealthy children has been increasing [1-3].

\footnotetext{
* Correspondence: Deepa.Mukundan@utoledo.edu

2Department of Pediatrics, Division of Infectious Diseases, The University of Toledo College of Medicine and Mercy Children's Hospital, 2222 Cherry

Street, Toledo-OH, 43608, USA

Full list of author information is available at the end of the article
}

CAMRSA strains as defined by the Centers for Disease Control and Prevention (CDC) clinical criteria [4] have some general characteristics that differentiate them from healthcare associated MRSA (HAMRSA) strains, including the presence of the Staphylococcal chromosomal cassette - SCCmec type IVa that confers methicillin resistance, lukSF-PV genes that codes for Panton-Valentine leukocidin (PVL), arginine catabolic mobile element (ACME) element that contributes to skin colonization [5], antibiotic resistance patterns [3], and pulsed field types (PFT) [6]. Several reports now show the migration of these CAMRSA strains into the hospital setting [7-9]. A six-fold increase in the number of MRSA infections among children between 2002 and 2007 ( $\mathrm{p}<0.0001)$ (Figure 1) prompted us to examine both the clinical profile of the patients, and the molecular profile of the

\section{Biomed Central}




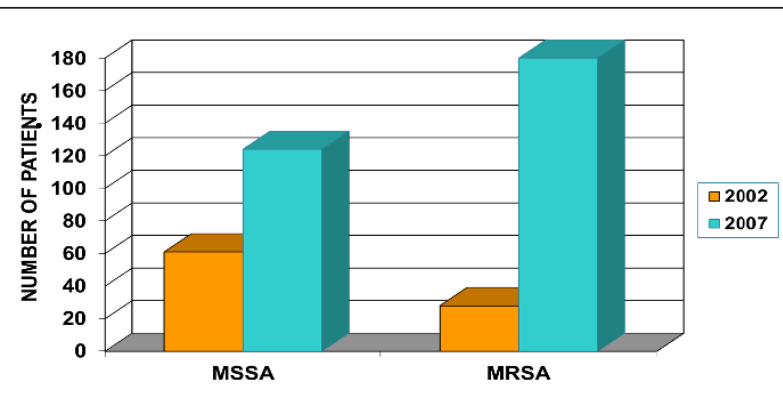

Figure 1 Comparison of Pediatric MRSA Incidence in two time periods five years apart: June 1st to Dec 31st 2002 and 2007 $(p<0.0001)$.

infecting strains at Mercy Children's Hospital Toledo, Ohio. We also compared two strain typing methods pulsed field typing (PFT) and the automated rapid typing method using repetitive sequence-based PCR, the DiversiLab system [10].

\section{Methods \\ MRSA isolate collection and patient medical record review}

This is a retrospective, descriptive, single-cohort study conducted at Mercy Children's Hospital, Toledo, Ohio and was approved by the institutional review board. Pediatric patients (< 18 yrs of age), who were culture positive for MRSA between June 1 to December 31, 2007, were identified by the clinical microbiology laboratory (Mercy Integrated Laboratories, Toledo, Ohio). This facility also provided us with a sample of the clinical isolate that had been frozen at $-80^{\circ} \mathrm{C}$ in a solution of $50 \%$ brain-heart infusion and $50 \%$ glycerol for later analysis.

Medical charts of these patients were reviewed for social and demographic information including age, gender, race, socio-economic status based on insurance, preexisting history of skin and soft tissue infection (SSTI); respiratory, cardiovascular, gastrointestinal, and nervous system diseases, type of care (outpatient $v s$. emergency room vs. inpatient care) and site of infection. Antimicrobial susceptibilities were determined based on Clinical and laboratory Standard Institute (CLSI) guidelines at the clinical laboratory using the Vitek system for oxacillin, erythromycin, clindamycin, vancomycin, ciprofloxacin, tetracycline, trimethoprim/sulfamethoxasole, rifampin and linezolid. All erythromycin-resistant strains were tested for inducible clindamycin resistance using the Dtest [11] before final susceptibilities were reported.

\section{Strain Typing}

Pulsed Field typing (PFT): Strain typing was done by PFT as described by Chang et al [12], using SmaI as the restriction enzyme, at the Children's Memorial Hospital,
Chicago, Illinois. The relatedness of isolates was based on visual comparison of band patterns by the use of criteria described by Tenover et al [13].

DiversiLab typing: Strain typing was also performed using the DiversiLab System at Mercy Integrated Laboratories. This is an automated method using repetitive sequence-based PCR that targets multiple noncoding repetitive sequences in the genomic DNA. Band patterns were subsequently analyzed using the webbased DiversiLab software [10].

\section{DNA Extraction and PCR}

Clinical isolates were grown on $5 \%$ blood agar plates overnight at $37^{\circ} \mathrm{C}$. DNA was extracted from the isolates using the Wizard ${ }^{\circledR}$ Genomic DNA Purification Kit. PCR amplification was then performed on all patient isolates for the presence of $m e c A$, SCCmec typing, $\operatorname{arcA}$, ACME, lukSF-PV and cap5 genes (Additional file 1) [14-17].

\section{Statistical Analysis}

Fisher's Exact test was used to explore for associations of site of infection, pre-existing SSTI and respiratory disease with age group and PFGE type. A Fisher's Exact p-value of $<0.05$ was considered statistically significant. Data were analyzed using SAS (SAS Cary, NC, version 9).

\section{Results}

From June 1, 2007 to December 31, 2007, 63 pediatric patients with MRSA infections were seen at the emergency room, outpatient clinics and the inpatient ward at Mercy Children's Hospital. Of these, only 5 patients did not meet the CDC clinical criteria for CAMRSA [4]. Thus, 58 (92\%) of all pediatric MRSA infections were community-acquired. All of these CAMRSA infections were SSTIs. During this time period there were no other culture positive invasive pediatric MRSA infections like bacteremia, sepsis, endocarditis, pneumonia, or osteomyelitis.

The patient characteristics for CAMRSA infections are shown in Table 1. The turnover of patients at Mercy Children's Hospital in 2007 was about 22,000 (inpatients 2400 ) pediatric patients. In 2007, 26\% of all children seen at Mercy Children's hospital were African American compared to $62 \%$ of our CAMRSA patients and; $51 \%$ were Medicaid insurance patients and therefore belonged to the lower socio economic group compared to $74 \%$ of our CAMRSA patients. All of these CAMRSA isolates were susceptible to trimethoprim/sulfamethoxasole, clindamycin, rifampin, linezolid and vancomycin.

The distribution of SSTI sites is shown in Table 2 and reflects an age associated shift. In children ages 0-3 years, 19 (76\%) had perineal SSTI which was more common. In contrast, only $2(11 \%)$ of the children ages $4-12$ 
Table 1 Patient Characteristics

\begin{tabular}{|c|c|}
\hline & n (\%) \\
\hline \multicolumn{2}{|l|}{ Age group (years) } \\
\hline $0-3$ & $25(43 \%)$ \\
\hline $4-12$ & $19(33 \%)$ \\
\hline $13-18$ & $14(24 \%)$ \\
\hline \multicolumn{2}{|l|}{ Gender } \\
\hline Female & $36(62 \%)$ \\
\hline Male & $22(38 \%)$ \\
\hline \multicolumn{2}{|l|}{ Race } \\
\hline Caucasian & $16(29 \%)$ \\
\hline African American & $34(62 \%)$ \\
\hline Other & $5(9 \%)$ \\
\hline \multicolumn{2}{|l|}{ Type of Visit } \\
\hline ER & $27(47 \%)$ \\
\hline Inpatient & $11(19 \%)$ \\
\hline Outpatient & $20(34 \%)$ \\
\hline \multicolumn{2}{|l|}{ Insurance } \\
\hline Private & $6(11 \%)$ \\
\hline Medicaid & $43(74 \%)$ \\
\hline Uninsured & $9(16 \%)$ \\
\hline \multicolumn{2}{|c|}{ Preexisting Conditions (patients may have more than 1) } \\
\hline SSTI & $24(41 \%)$ \\
\hline Respiratory Disease & $22(38 \%)$ \\
\hline Gastrointestinal & $9(16 \%)$ \\
\hline Cardiovascular & $3(5 \%)$ \\
\hline Nervous system & $1(2 \%)$ \\
\hline None & 19 (33\%) \\
\hline \multicolumn{2}{|l|}{ Site of Infection } \\
\hline Face & $4(7 \%)$ \\
\hline Lower extremity & 18 (31\%) \\
\hline Perineal & $21(36 \%)$ \\
\hline Trunk & $4(7 \%)$ \\
\hline Upper extremity & 11 (19\%) \\
\hline
\end{tabular}

ER: Emergency room, SSTI: Skin and soft tissue infection had perineal SSTI and none of the 13-18 year olds. Infections in the extremities were more common in the older youth compared to the youngest children: 3 (12\%) in ages $0-3,13(68 \%)$ in ages 4-12, and 13 (93\%) in ages 13-18. Overall, there was a significant association between site of the infection and age group (Fisher's Exact p-value $<0.001$ ) (Table 2).

Nineteen (33\%) children had no pre-existing condition. Age group was not associated with having either respiratory disease or SSTI as a pre-existing condition (Fisher's Exact p-values > 0.05 - Table 2). Pulsed field typing (Smal PFT) of the 58 CAMRSA isolates revealed that they were all USA300 PFT with seven different subtypes (Figure 2), and one sub-type dominated in $72 \%$ (n = 42) (Table 3). PFGE sub-type I (compared to subtypes 2-7) was not associated with site of infection or with having respiratory disease or SSTI as a pre-existing condition, all with Fisher's Exact p-values > 0.05 (Table 4). The DiversiLab typing of the 58 CAMRSA strains revealed that 55 (95\%) were indeed USA300 PFT while 3 strains were identified as USA 500.

All 58 CAMRSA strains were mecA and lukSF-PV positive, with SCCmec type IVa; 56 (97\%) contained ACME and the cap5 gene was present in 46 (79\%) (Table 3). We observed that all the cap5 negative strains belonged to a single USA300 PFT pattern (Table 3 and Figure 2).

\section{Discussion}

Figure 1 clearly demonstrates a six fold increase in the incidence of pediatric MRSA infections from 2002 to 2007 ( $\mathrm{p}<0.0001$ ). A clear majority of our pediatric MRSA infections were CAMRSA, which is consistent with the trend reported for the United States [18] and Europe [19,20].

A significant association of age with site of infection has for the first time been demonstrated in our study.

Table 2 Associations with Age Group

\begin{tabular}{lcccc}
\hline & $\begin{array}{c}\text { Age } \mathbf{0 - 3} \\
\mathbf{N}=\mathbf{2 5}\end{array}$ & $\begin{array}{c}\text { Age 4-12 } \\
\mathbf{N}=\mathbf{1 9}\end{array}$ & $\begin{array}{c}\text { Age 13-18 } \\
\mathbf{N}=\mathbf{1 4}\end{array}$ & Fisher's Exact Two-tailed P-value \\
\hline Site of Infection & & & & $<0.001$ \\
Face & $2(8 \%)$ & $1(5 \%)$ & $1(7 \%)$ & \\
Lower extremity & $2(8 \%)$ & $8(42 \%)$ & $8(57 \%)$ & \\
Perineal & $19(76 \%)$ & $2(11 \%)$ & $0(0 \%)$ & $0(0 \%)$ \\
Trunk & $1(4 \%)$ & $3(16 \%)$ & $5(36 \%)$ & 0.42 \\
Upper extremity & $1(4 \%)$ & $5(26 \%)$ & 0.25 \\
\hline Respiratory disease pre-existing condition & $7(28 \%)$ & $9(47 \%)$ & $6(43 \%)$ & 0.59 \\
\hline SSTI pre-existing condition & $12(48 \%)$ & $9(47 \%)$ & $3(21 \%)$ & $9(64 \%)$ \\
\hline PFT Sub-type 1 (compared to types 2-7 combined) & $19(79 \%)$ & $14(74 \%)$ & & \\
\hline
\end{tabular}

PFT: Pulse field type, SSTI: Skin and soft tissue infection 


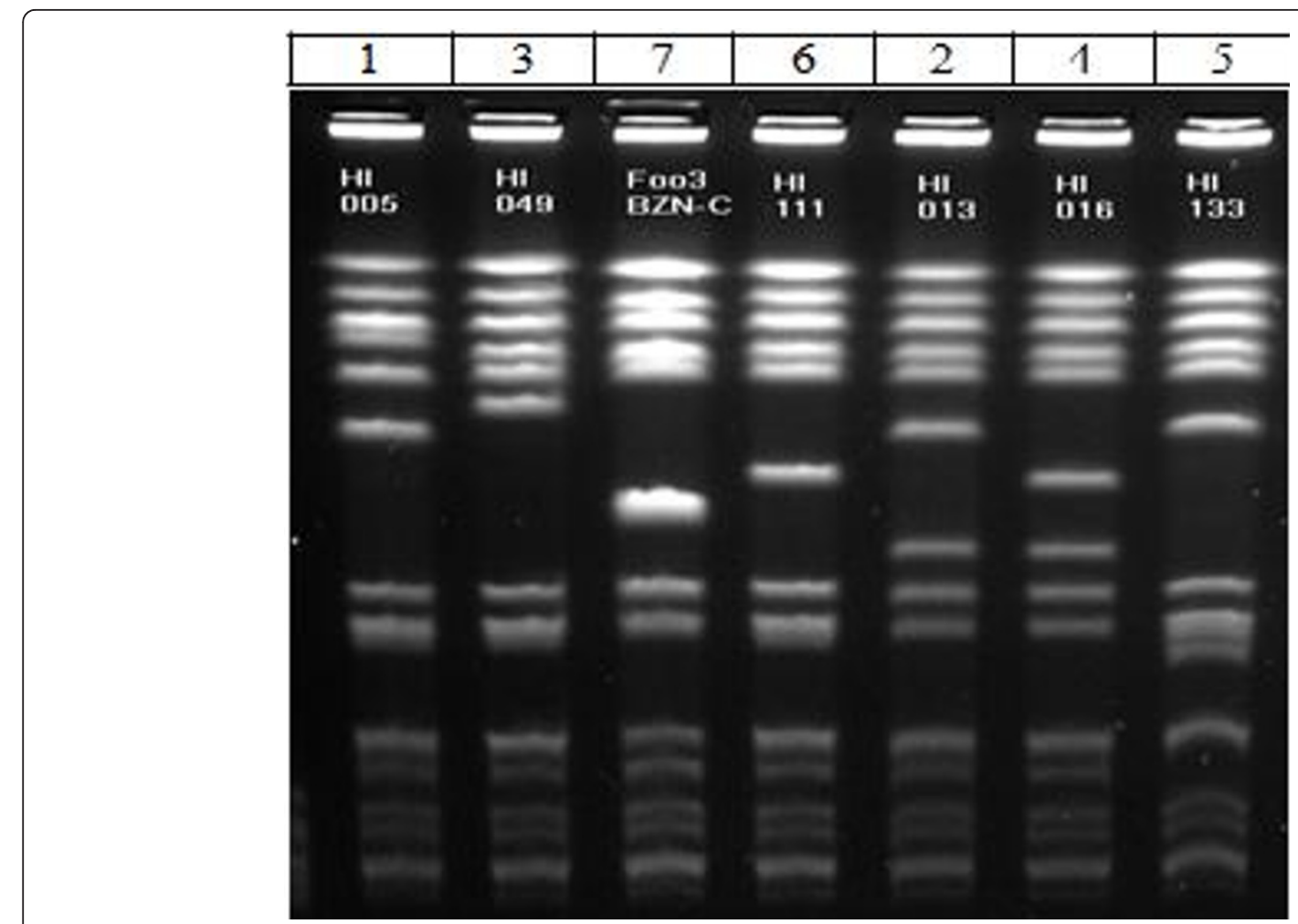

Figure 2 USA300 PFT subtypes. This is a picture of the USA300 strains all run on a single gel and are labeled according to the PFT subtypes in Table 2,3 \& 4 .

Perineal MRSA colonization in children has been recorded in the daycare setting [21]. Koski et al indicate that pediatric perineal infections with MRSA are increasing [22]. We found that such infections were more common to the 0-3 y-old cohort. This age preference could be due to increased rates of perineal CAMRSA colonization in this age group, but may also reflect use of diapers and possible dermabrasion caused by vigorous wiping of the area during diaper changes or both. Transfer of vancomycin resistance gene van $\mathrm{A}$ from vancomycin resistant Enterococcus to MRSA has been shown to occur in vitro and in vivo [23]. Perineal CAMRSA infection in children could contribute to the emergence of vancomycin resistant S.aureus strains when co-colonized with vancomycin resistant Enterococcus [24].

Of interest, all of the CAMRSA strains in our study were susceptible to clindamycin, contrary to higher rates

Table 3 Molecular epidemiology of USA300 PFT strains $(\mathbf{n}=\mathbf{5 8})$

\begin{tabular}{|c|c|c|c|c|c|c|}
\hline USA300 PFT subtypes n(\%) & Diversilab type* $\mathrm{n}(\%)$ & mecA & SCCmec type & ACME & lukSF-PV & cap5 \\
\hline $1-42(72 \%)$ & $\begin{array}{l}\text { USA300-41(98\%) } \\
\text { USA500-1(24\%) }\end{array}$ & 42 & IVa-42 & 42 & 42 & $30(71 \%)$ \\
\hline $2-6(10 \%)$ & $\begin{array}{l}\text { USA300-4(67\%) } \\
\text { USA500-2(33\%) }\end{array}$ & 6 & IVa-6 & 6 & 6 & 6 \\
\hline $3-4(7 \%)$ & USA300-4 & 4 & IVa-4 & 4 & 4 & 4 \\
\hline $4-2(3 \%)$ & USA300-2 & 2 & IVa-2 & 1 & 2 & 2 \\
\hline $5-2(3 \%)$ & USA300-2 & 2 & IVa-2 & 2 & 2 & 2 \\
\hline $6-1(2 \%)$ & USA300-1 & 1 & IVa-1 & 0 & 1 & 1 \\
\hline $7-1(2 \%)$ & USA300-1 & 1 & IVa-1 & 1 & 1 & 1 \\
\hline Total(n) & 58(100\%) & $\mathbf{5 8}(100 \%)$ & $\mathbf{5 8}(100 \%)$ & 56(97\%) & 58(100\%) & 46(79\%) \\
\hline
\end{tabular}

PFT: Pulsed field type; SCC: Staphylococcal Cassette Chromosome, lukSF-PV genes that encode Panton-Valentine leukocidin (PVL), ACME: Arginine catabolic mobile element.

*The DiversiLab strain types are named as corresponding PFT's based on a standardized comparison.

For USA300 PFT subtypes please see figure 2. 


\begin{tabular}{lccc}
\hline & PFT Sub-type $\mathbf{1} \mathbf{N}=\mathbf{4 2}$ & PFT Sub-types 2-7 N = 16 & Fisher's Exact Two-tailed P-value \\
\hline Site of Infection & $2(5 \%)$ & $2(13 \%)$ & 0.35 \\
Face & $11(26 \%)$ & $7(43 \%)$ & \\
Lower extremity & $16(38 \%)$ & $5(31 \%)$ & $0(0 \%)$ \\
Perineal & $4(10 \%)$ & $2(13 \%)$ & 0.54 \\
Trunk & $9(21 \%)$ & $7(47 \%)$ & 1.0 \\
Upper extremity & $15(36 \%)$ & $6(40 \%)$ & \\
\hline Respiratory disease pre-existing condition & $18(43 \%)$ & & \\
\hline SSTI pre-existing condition &
\end{tabular}

PFT: Pulse field type, SSTI: Skin and soft tissue infection

of resistance reported for Alaska, Houston and San Francisco [25-27].

Strain typing of our patients' MRSA isolates supports the observation that USA300 PFT is the most common causative strain and is clonal [27]. The molecular characteristics of our isolates were similar to the USA300 strains from other published reports in that they were SCCmec type IVa and lukSF-PV positive [27,28]. 56/58 of the strains were also positive for ACME, a novel mobile genetic region predominantly reported in USA300 MRSA strains that potentially enhance colonization and virulence [29]. We observed that all the 12 strains that were cap5 gene negative belonged to the predominant USA300 PFT subtype (Table 3 and Figure 2). cap5 gene encodes for a capsule that enhances the virulence of Staphylococcus aureus. It has been used as vaccine target. The clinical significance of cap5 negative strains in our study is unclear at this time.

Typing using the DiversiLab system is rapid and user friendly compared to PFT. However, differentiating PFT USA300 from USA500 is tricky using DiversiLab [30]. Of interest, $3 / 3$ isolates identified by PFT as USA300 were mis-identified by DiversiLab as USA500. These isolates were also positive for ACME which is a mobile genetic element that is thought to be acquired by USA300 as it evolved from its progenitor USA500 [31].

\section{Conclusion}

The incidence of CAMRSA infection is increasing in the pediatric population of Northwest Ohio. SSTIs are the most common type of infection and among children $<3$ years of age with perineal SSTIs being the dominant form caused by strain USA300 PFT that carries the SCCmec type IVa, lukSF-PV gene and ACME. The automated rapid strain typing method, the DiversiLab system, is not as discriminative as PFT.

Further investigations are needed to assess the extent of USA300 perineal colonization in toddlers and to identify unique virulence characteristics to develop strategies for prevention and treatment of these infections.

\section{Additional material}

Additional file 1: Primers used for the PCR reactions for mecA, SCCmec typing, arcA, ACME, lukSF-PV and cap5 genes. Details of the sequences of all the primers used in this study along with the references are in the file.

\section{Abbreviations}

ACME: Arginine catabolic mobile element; CAMRSA: Community-acquired methicillin resistant Staphylococcus aureus; MRSA: Methicillin resistant Staphylococcus aureus; PCR: Polymerase chain reaction; PFT: Pulsed field type (or) pulsed field gel electrophoresis; S.aureus: Staphylococcus aureus; SSTI: Skin and soft tissue infection.

\section{Acknowledgements}

I would like to thank Jan Tucker of Mercy Integrated Laboratories and Dr. John Schaeufele, President and CEO of Mercy Children's Hospital for their support. Nancy Buderer helped with the statistical analysis.

\section{Author details}

${ }^{1}$ The University of Toledo College of Medicine, 3000 Arlington Avenue, Toledo-OH, 43614, USA. ²Department of Pediatrics, Division of Infectious Diseases, The University of Toledo College of Medicine and Mercy Children's Hospital, 2222 Cherry Street, Toledo-OH, 43608, USA. ${ }^{3}$ Mercy Integrated Laboratories, 2222 Cherry Street, Toledo-OH, 43608, USA. ${ }^{4}$ Department of Pediatrics, Division of Infectious Diseases, Children's Memorial Hospital, 2300 Children's Plaza, Chicago-IL 60614-3363, USA. ${ }^{5}$ Department of Medical Microbiology and Immunology, The University of Toledo College of Medicine, 3000 Arlington Avenue, Toledo-OH, 43614, USA. ${ }^{6}$ Program in Bioinformatics \& Proteomics/Genomics, The University of Toledo College of Medicine, 3000 Arlington Avenue, Toledo-OH, 43614, USA.

\section{Authors' contributions}

AM conducted patient chart review, ran PCR tests and wrote the first draft of the manuscript. MS did the collection and freezing of MRSA samples and ran $P C R$ tests. $X Z$ ran $P C R$ tests and managed the MRSA database. JH did the DiversiLab typing. WK conducted the pulsed field gel typing experiments. RY was involved in the concept of the study and reviewed the manuscript. RB was involved in the concept of the study; contributed his expertise in conducting the PCR experiments; edited and reviewed the manuscript; and mentored medical students AM and MS in the laboratory. DM was the principal investigator and was involved in the concept, planning and coordination of the study. She also mentored medical students AM and MS. In addition, she was responsible for writing, editing and submission of the manuscript. All authors read and approved the final manuscript.

\section{Competing interests}

The authors declare that they have no competing interests. 
Received: 31 January 2011 Accepted: 27 October 2011

Published: 27 October 2011

\section{References}

1. Chambers HF: The changing epidemiology of S. aureus? Emerg Infect Dis 2001, 7:178-82.

2. Zetola N, Francis JS, Nuermberger EL, Bishai WR: CAMRSA: An emerging threat. Lancet Infect Dis 2005, 5:275-86.

3. Shapiro A, Raman S, Johnson M, Piehl M: CAMRSA infections in North Carolina children: prevalence, antibiotic sensitivities, and risk factors. N C Med J 2009, 70:102-7.

4. Naimi TS, LeDell KH, Como-Sabetti K, Borchardt SM, Boxrud DJ, Etienne J, et al: Comparison of community- and health care-associated MRSA infection. JAMA 2003, 290:2976-84.

5. Goering RV, McDougal LK, Fosheim GE, Bonnstetter KK, Wolter DJ, Tenover FC: Epidemiologic distribution of the ACME among selected methicillin-resistant and methicillin-susceptible S.aureus isolates. J Clin Microbiol 2007, 45:1981-4.

6. King MD, Humphrey BJ, Wang YF, Kourbatova EV, Ray SM, Blumberg HM: Emergence of CAMRSA USA 300 clone as the predominant cause of SSTI. Ann Intern Med 2006, 144:309-17.

7. Chua K, Laurent F, Coombs G, Grayson ML, Howden BP: Antimicrobial resistance: Not community-associated methicillin-resistant Staphylococcus aureus (CA-MRSA)! A clinician's guide to community MRSA - its evolving antimicrobial resistance and implications for therapy. Clin Infect Dis [Research Support, Non-U.S. Gov't Review] 2011, 52(1):99-114.

8. Reygaert W: Methicillin-resistant Staphylococcus aureus (MRSA): prevalence and epidemiology issues. Clin Lab Sci 2009, 22(2):111-4.

9. Moore $\mathrm{CL}$, Hingwe A, Donabedian SM, Perri MB, Davis SL, Haque NZ, et al: Comparative evaluation of epidemiology and outcomes of methicillinresistant Staphylococcus aureus (MRSA) USA300 infections causing community- and healthcare-associated infections. Int J Antimicrob Agents. [Comparative Study] 2009, 34(2):148-55.

10. Shutt CK, Pounder JI, Page SR, Schaecher BJ, Woods GL: Clinical evaluation of the DiversiLab microbial typing system using repetitive-sequencebased PCR for characterization of S.aureus strains. J Clin Microbiol 2005, 43:1187-92.

11. Lewis JS, Jorgensen $\mathrm{JH}$ : Inducible clindamycin resistance in Staphylococci: should clinicians and microbiologists be concerned? Clin Infect Dis 200(40):280-5.

12. Chang N, Chui L: A standardized protocol for the rapid preparation of bacterial DNA for pulsed field electrophoresis. Diagn Microbiol Infect Dis 1998, 31:275-9.

13. Tenover FC, Arbeit RD, Goering RV, Mickelsen PA, Murray BE, Persing DH, et al: Interpreting chromosomal DNA restriction patterns produced by pulsed-field gel electrophoresis: criteria for bacterial strain typing. J Clin Microbiol 1995, 33:2233-9.

14. Oliveira DC, de Lencastre H: Multiplex PCR strategy for rapid identification of structural types and variants of the mec element in MRSA. Antimicrob Agents Chemother 2002, 46:2155-61.

15. Zhang K, McClure JA, Elsayed S, Louie T, Conly JM: Novel multiplex PCR assay for characterization and concomitant subtyping of SCC mec types I to V in MRSA. J Clin Microbiol 2005, 43:5026-33.

16. Lina G, Piemont $Y$, Godail-Gamot F, Bes M, Peter MO, Gauduchon V, et al: Involvement of PVL-producing S.aureus in primary skin infections and pneumonia. Clin Infect Dis 1999, 29:1128-32.

17. Moore PC, Lindsay JA: Genetic variation among hospital isolates of methicillin-sensitive S.aureus: evidence for horizontal transfer of virulence genes. J Clin Microbiol 2001, 39:2760-7

18. Como-Sabetti K, Harriman KH, Buck JM, Glennen A, Boxrud DJ, Lynfield R: CAMRSA: trends in case and isolate characteristics from six years of prospective surveillance. Public Health Rep 2009, 124:427-35.

19. Faria NA, Oliveira DC, Westh $H$, Monnet DL, Larsen AR, Skov $R$, et al: Epidemiology of emerging MRSA in Denmark: A nationwide study in a country with low prevalence of MRSA infection. J Clin Microbiol 2005, 43:1836-42.

20. Vourli S, Perimeni D, Makri A, Polemis M, Voyiatzi A, Vatopoulos A: CAMRSA infections in a paediatric population in Greece. Euro Surveill 2005, 10:78-9.

21. Shahin R, Johnson IL, Jamieson F, McGeer A, Tolkin J, Ford-Jones EL: MRSA carriage in a child care center following a case of disease. Toronto Child Care Center Study Group. Arch Pediatr Adolesc Med 1999, 153:864-8.
22. Koski ME, DeMarco RT, Brock JW, Pope JC, Adams MC, Thomas JC: Community associated methicillin resistant staphylococcal infections in a pediatric urology practice. J Urol 2008, 179:1098-101.

23. Perichon B, Courvalin P: VanA-type vancomycin-resistant S.aureus. Antimicrob Agents Chemother 2009, 53:4580-7.

24. Warren DK, Nitin A, Hill C, Fraser VJ, Kollef MH: Occurrence of cocolonization or co-infection with vancomycin-resistant enterococci and MRSA in a medical intensive care unit. Infect Control Hosp Epidemiol 2004, 25:99-104.

25. Diep BA, Chambers HF, Graber CJ, Szumowski JD, Miller LG, Han LL, et al: Emergence of multidrug-resistant, CAMRSA clone USA300 in men who have sex with men. Ann Intern Med 2008, 148:249-57.

26. Kaplan SL, Hulten KG, Gonzalez BE, Hammerman WA, Lamberth L, Versalovic J, et al: Three-year surveillance of CAMRSA infections in children. Clin Infect Dis 2005, 40:1785-91.

27. David MZ, Rudolph KM, Hennessy TW, Boyle-Vavra S, Daum RS: Molecular epidemiology of MRSA, rural southwestern Alaska. Emerg Infect Dis 2008 14:1693-9.

28. Jones RN, Nilius AM, Akinlade BK, Deshpande LM, Notario GF: Molecular characterization of S.aureus isolates from a 2005 clinical trial of uncomplicated skin and skin structure infections. Antimicrob Agents Chemother 2007, 51:3381-4.

29. Diep BA, Stone GG, Basuino L, Graber CJ, Miller A, des Etages SA, et al: The ACME and SCCmec linkage: convergence of virulence and resistance in the USA300 clone of MRSA. J Infect Dis 2008, 197:1523-30,

30. Library Stats Sheet: MRSA. 2008 BioMerieux Inc. BBI-019-08. [http://www. biomerieux-usa.com/upload/BBI-019-08\%20LSS\%20MRSA\%20v3-1.pdf], Accessed April 6, 2010.

31. Li M, Diep BA, Villaruz AE, Braughton KR, Jiang $X$, DeLeo FR, et al: Evolution of virulence in epidemic community-associated methicillin-resistant Staphylococcus aureus. Proc Natl Acad Sci USA 2009, 106(14):5883-8.

\section{Pre-publication history}

The pre-publication history for this paper can be accessed here: http://www.biomedcentral.com/1471-2431/11/96/prepub

doi:10.1186/1471-2431-11-96

Cite this article as: McCullough et al.: Higher incidence of perineal community acquired MRSA infections among toddlers. BMC Pediatric 2011 11:96

\section{Submit your next manuscript to BioMed Central and take full advantage of:}

- Convenient online submission

- Thorough peer review

- No space constraints or color figure charges

- Immediate publication on acceptance

- Inclusion in PubMed, CAS, Scopus and Google Scholar

- Research which is freely available for redistribution

Submit your manuscript at www.biomedcentral.com/submit
C Biomed Central 